\title{
LOW-FREQUENCY NOISE OF NEAR UV LEDS
}

\author{
J. Glemža, S. Pralgauskaitė, V. Palenskis, and J. Matukas \\ Institute of Applied Electrodynamics and Telecommunications, Vilnius University, Saulètekio 3, 10257 Vilnius, Lithuania \\ Email: justinas.glemza@ff.vu.lt; sandra.pralgauskaite@ff.vu.lt; vilius.palenskis@ff.vu.lt; jonas.matukas@ff.vu.lt
}

Received 17 May 2019; revised 27 June 2019; accepted 30 September 2019

\begin{abstract}
Low-frequency noise characteristics of high power near ultraviolet light-emitting diodes (LEDs) with peak radiative wavelengths in a range of $380-410 \mathrm{~nm}$ are investigated in a temperature interval of $110-293 \mathrm{~K}$. The defect-assisted tunnelling current component has been observed in some $380 \mathrm{~nm}$ peak wavelength samples with corresponding Lorentzian-type electrical noise spectra. Other samples (with a peak wavelength of 390-410 nm) have mainly $1 / f^{\alpha}$-type electrical fluctuations. Cross-correlation coefficient analysis between electrical and optical fluctuations has been performed in order to evaluate whether the observed defect levels, responsible for additional generation-recombination $(g-r)$ noise components in LEDs noise spectra, are related to the active layer or to the peripheral area of the device. Activation energies of these $g-r$ centres have been also evaluated using $g-r$ noise spectroscopy.
\end{abstract}

Keywords: cross-correlation coefficient, fluctuation, light-emitting diode, noise, tunnelling

PACS: $72.70 .+\mathrm{m}, 85.60 . \mathrm{Jb}$

\section{Introduction}

Due to numerous advantages, such as a small size and increased efficiency, ultraviolet (UV) lightemitting diodes (LEDs) have gained a lot of demand for applications in UV lighting, as light sources for microscopes and for chemical excitation in medicine and biotechnology, for sterilization and disinfection, for banknote identification, counterfeit detection, etc. [1-3]. For the fabrication of near UV (300-400 nm) light-emitting diodes [1], the InGaN material system is of a high importance. It is well known that non-uniformities in the indium concentration in InGaN/GaN quantum wells (QWs) create localized states which are responsible for the effective radiative recombination [4 4, 5]. However, near UV LEDs contain less indium, and this results in a lower radiative efficiency and, at the same time, in an increased impact of threading dislocations on the overall performance of the UV emitter [3, 6 ].

Low-frequency excess noise is very sensitive for defectiveness and fabrication imperfections of semiconductor devices. Usually, the level of electrical $1 / f$-type fluctuations (flicker noise) of LEDs is much higher than the level of shot noise or thermal noise in the low-frequency region (up to $10 \mathrm{MHz}$ for modern devices) [7]. In some cases, when generation-recombination $(g-r)$ noise with the Lorentzian-type spectrum is observed, it helps one to identify the energy levels of localized centres. $1 / f$-type fluctuations not only characterize the quality of the semiconductor crystal, but also the dependence of noise spectral density on the current reveals information about the current flowing through the sample paths. For InGaN material system based devices, which suffer from a high density of defects, this investigation is crucial [8-11]. What is more, for the characterization of optoelectronic devices, e. g. LEDs or laser diodes (LDs), it is important to identify the location of noise sources in the structure. This would allow one to discover the relation between the lowfrequency noise characteristics and the indium amount in QWs that determines the emission wavelength in near UV LEDs. However, the presence of additional noise sources in the LED peripheral area usually aggravates this analysis. In 
our previous works [11, 12] it has been demonstrated that the cross-correlation analysis between electrical and optical fluctuations together with the evaluation of other electrical, e. g. currentvoltage $(I-U)$, characteristics is a powerful tool for the characterization of green and white LEDs. The ability to determine the location of noise sources in LDs or LEDs when measurements are performed under the normal bias condition near the equilibrium state makes the low-frequency noise and cross-correlation analysis method highly attractive.

Despite the fact that near UV LEDs with a sufficiently high external quantum efficiency have been already demonstrated [1], their low-frequency noise has not been studied enough [13]. The impact of fluctuation origins and defects that are present in the structure on the LED conduction mechanism and overall performance still needs to be researched in a more detailed way. The aim of this work is not only to investigate the low-frequency noise characteristics of the near UV LEDs, but also to identify the location of the sources of Lorentzian-type fluctuations in the near UV LEDs of different emission wavelength using cross-correlation analysis between the electrical and optical fluctuations.

\section{Experimental details and investigated devices}

Low-frequency noise characteristics such as electrical noise - the terminal voltage fluctuations of LED $(10 \mathrm{~Hz}-100 \mathrm{kHz})$, optical noise - fluctuations of the emitted light power detected by a UV-blue pin photodiode $(10 \mathrm{~Hz}-20 \mathrm{kHz})$, and the cross-correlation between electrical and optical fluctuations $(10 \mathrm{~Hz}-20 \mathrm{kHz})$ were measured under constant current operation at the forward bias at room temperature (RT). When generation-recombination noise spectroscopy was performed, cooling by liquid nitrogen was used and measurements were performed in a temperature interval of 110-293 K. For the measurement of current-voltage characteristics a precision source/ measure unit Keysight B2901 was used. Emitted light spectra were registered by an optical spectrum analyzer Advantest Q8341. A detailed noise measurement scheme can be found in our previous work [11].

The investigated high power $(\sim 1 \mathrm{~W}) \mathrm{InGaN}$ based near UV LEDs are summarized in Table 1 .
The light output power characteristics and optical spectra of the investigated LEDs are presented in Fig. 1. The measurements show that the LEDs with the highest amount of In in QWs and, therefore, the largest wavelength (group D) have the most symmetrical optical spectrum (Fig. 1(a)), while the samples with the lowest amount of In and the shortest wavelength (group A) have the lowest light output power (Fig. 1. (b)).

Table 1. Families of the investigated LEDs grouped by peak radiative wavelength.

\begin{tabular}{ccccc}
\hline $\begin{array}{c}\text { Peak } \\
\text { wavelength }\end{array}$ & $\sim 380 \mathrm{~nm}$ & $\sim 390 \mathrm{~nm}$ & $\sim 400 \mathrm{~nm}$ & $\sim 410 \mathrm{~nm}$ \\
\hline $\begin{array}{c}\text { Group } \\
\text { name }\end{array}$ & A & B & C & D \\
\hline
\end{tabular}
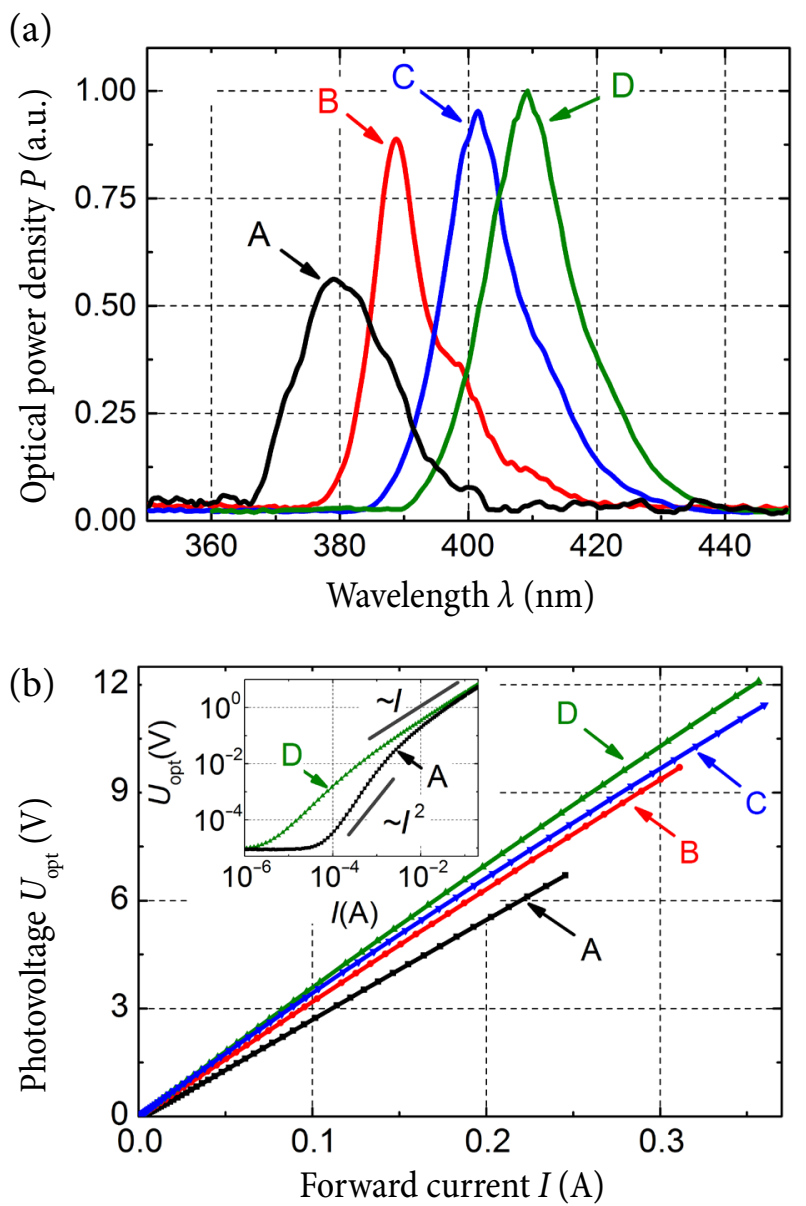

Fig. 1. Typical optical spectra of the investigated LEDs measured at $250 \mathrm{~mA}$ forward current (a); the emitted light output power (which is proportional to the photovoltage $U_{\text {opt }}$ of the load resistance of a photodetector) vs the current characteristics for different LEDs (b). The inset represents the latter characteristics of group A and D LEDs in a log-log scale. 


\section{Results and discussion}

\subsection{Analysis of the tunnelling current component}

For the analysis of the electrical characteristics of InGaN-based LEDs, the determination of the conduction mechanism is very important [6, 14-18] and it also broadens the interpretation of low-frequency fluctuations.

As presented in Fig. 2, the $I-U$ characteristic of particular LEDs from the group A (AI curve) differs from that of the remaining samples from this group (AII curve) and from other diodes of groups B-D. For the evaluation of the LED conduction process, the method described in [14] and [16] was used. The $I-U$ relation for the tunnelling through defects is expressed as

$$
I \sim P \cdot E^{2} \exp (-1 / E)
$$

where $I$ is the forward current, $P$ has a meaning of the tunnelling probability between defects, which is temperature independent, and $E$ is the electric field [14]. Thus, for only tunnelling current component existence, the $\log \left(I / U^{2}\right)$ dependence on $1 / U$ should be linear and the characteristic energy $E_{\mathrm{T}}=n k T$ in the $I-U$ relation $I=I_{0} \exp \left(q U / E_{\mathrm{T}}\right)$ should be temperature independent. Here $I_{0}$ is the saturation current of the diode, $q$ is the elementary charge, $n$ is the non-ideality coefficient, and $k$ is the Boltzmann constant. The energy $E_{\mathrm{T}}$ reflects the transparency of the energy barrier for the tunnelling process [14, 17].

The described procedure has been applied to the characteristics of the LEDs under investigation. The $I-U$ curves of the AI sample at different temper-

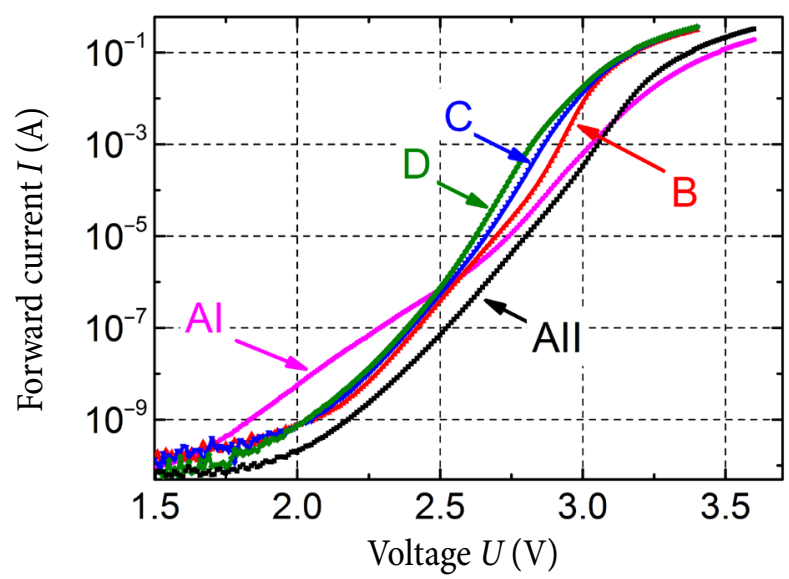

Fig. 2. $I-U$ characteristics of different wavelength LEDs at RT. atures are presented in Fig. 3, and the linear $\log \left(I / U^{2}\right)$ vs $1 / U$ dependences are also depicted in Fig. 4(a). The characteristic energy $E_{\mathrm{T}}$ of the particular LEDs

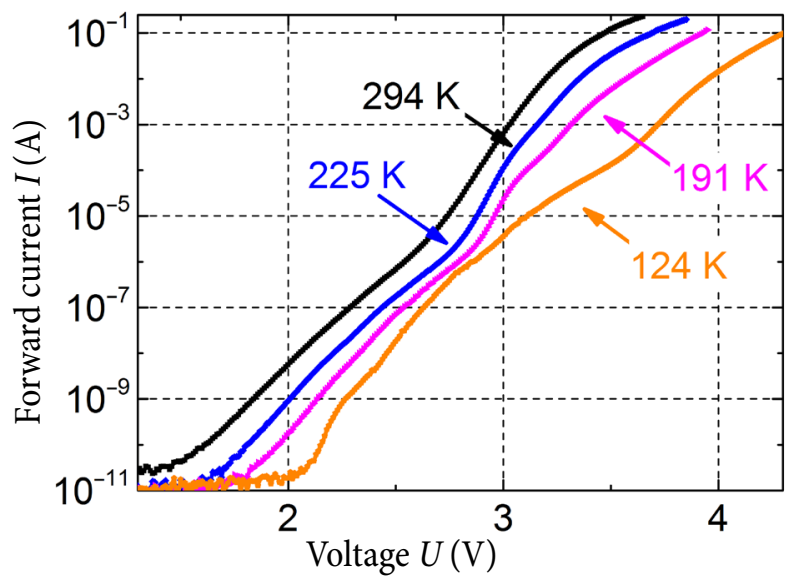

Fig. 3. $I-U$ characteristics of AI LED in a temperature range of $124-294 \mathrm{~K}$.
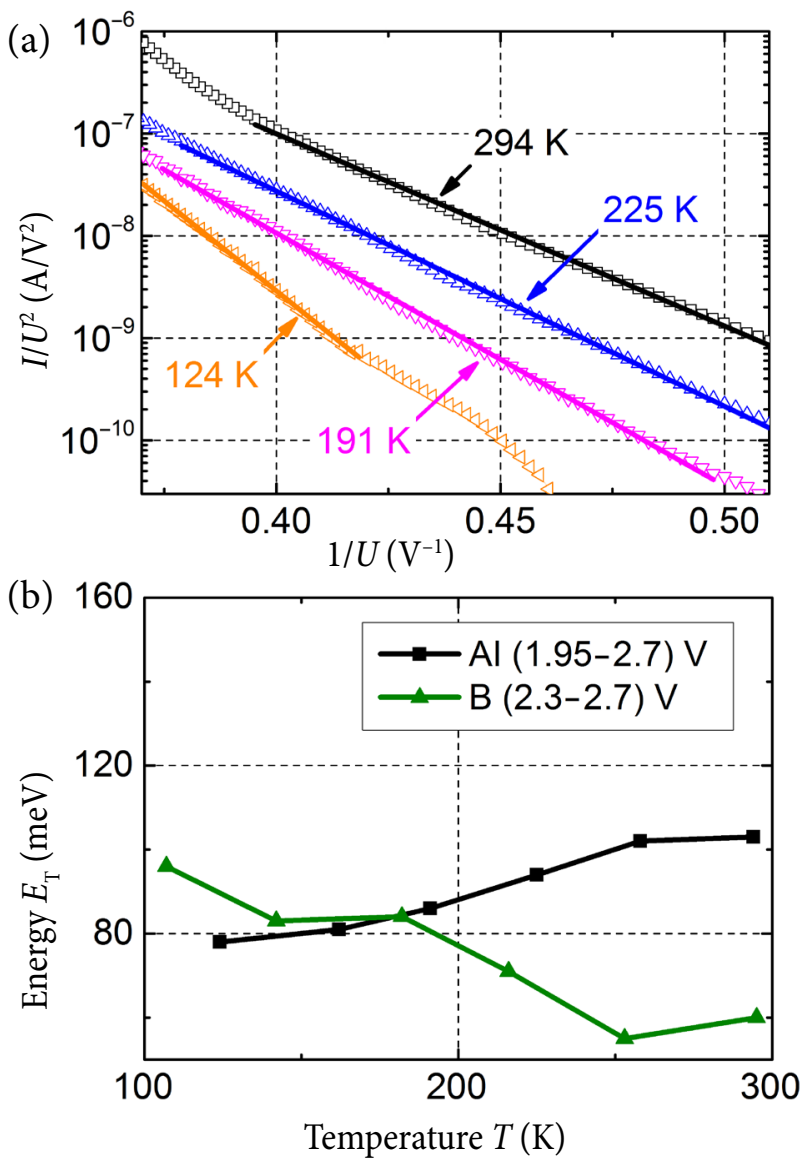

Fig. 4. (a) $I / U^{2}$ vs $1 / U$ curves of AI LED in a low bias regime in a temperature range of 124-294 K (solid lines represent the linear approximation). (b) Comparison of the characteristic energy $E_{\mathrm{T}}$ dependences on the temperature of AI LED and LED from the group $\mathrm{B}$ in $1.95-2.7 \mathrm{~V}$ and $2.3-2.73 \mathrm{~V}$, respectively, forward bias intervals. 
from the group A has been found to be higher than that of the samples from other investigated groups, e. g. $\sim 100 \mathrm{meV}$ (for AI) in comparison to $\sim 60 \mathrm{meV}$ (for B) at RT in a low bias regime (up to $\sim 2.7 \mathrm{~V}$ ). Other samples of the A family, group $\mathrm{C}$ and $\mathrm{D}$ LEDs have similar $E_{\mathrm{T}}$ dependences on temperature as the group B sample presented in Fig. 4(b). The variation of the characteristic energy $E_{\mathrm{T}}$ with temperature for the AI LED is weaker compared to, for example, that of the group B sample. High $E_{\mathrm{T}}$ indicates the high non-ideality factor of $I-U$ relation $(n \approx 4$ at RT) of the diode, also suggesting that some LEDs of the group A have a dominant tunnelling current component at a low bias [14. At higher bias the conduction is mixed of diffusion, recombination and tunnelling processes. No clear tunnelling current component has been observed in the samples of families B-D at a low bias.

The obtained results suggest that the quality of some samples from the group A is lower, i.e. they have a higher density of defects mainly such as threading dislocations and defects in the vicinity of them. This would allow one to explain the tunnelling process through the deep trap levels [17]. However, further analysis is needed to conclude this, thus, low-frequency noise investigation has been performed. Here in the group A the samples with the observed tunnelling component are denoted as AI, and LEDs without it as AII.

\subsection{Noise characteristics}

The electrical noise spectra of the investigated LEDs are presented in Figs. 5 and 6. Lorentziantype fluctuations (with a small $1 / f^{\alpha}$ noise component up to $\sim 1 \mathrm{kHz}$ ) in the whole investigated forward current region were observed only in the AI LEDs noise spectra (Fig. 5(a)). Such type noise spectrum usually indicates the presence of a discrete generation-recombination $(g-r)$ centre in the device. The trapping level with shorter than $\sim 1.6 \mu$ s effective relaxation time $\left(1 / \tau=1 / \tau_{\mathrm{e}}+1 /\right.$ $\tau_{c}$, where $\tau_{\mathrm{c}}$ and $\tau_{\mathrm{e}}$ are the average charge carrier capture and emission times from the defect level, respectively [19]) is responsible for the observed Lorentzian-type noise spectra. Regarding the fact that $\mathrm{g}-\mathrm{r}$ noise is also observed at a low bias for AI LEDs, it can be stated that the observed trapping level acts as an intermediate state for the tunnelling
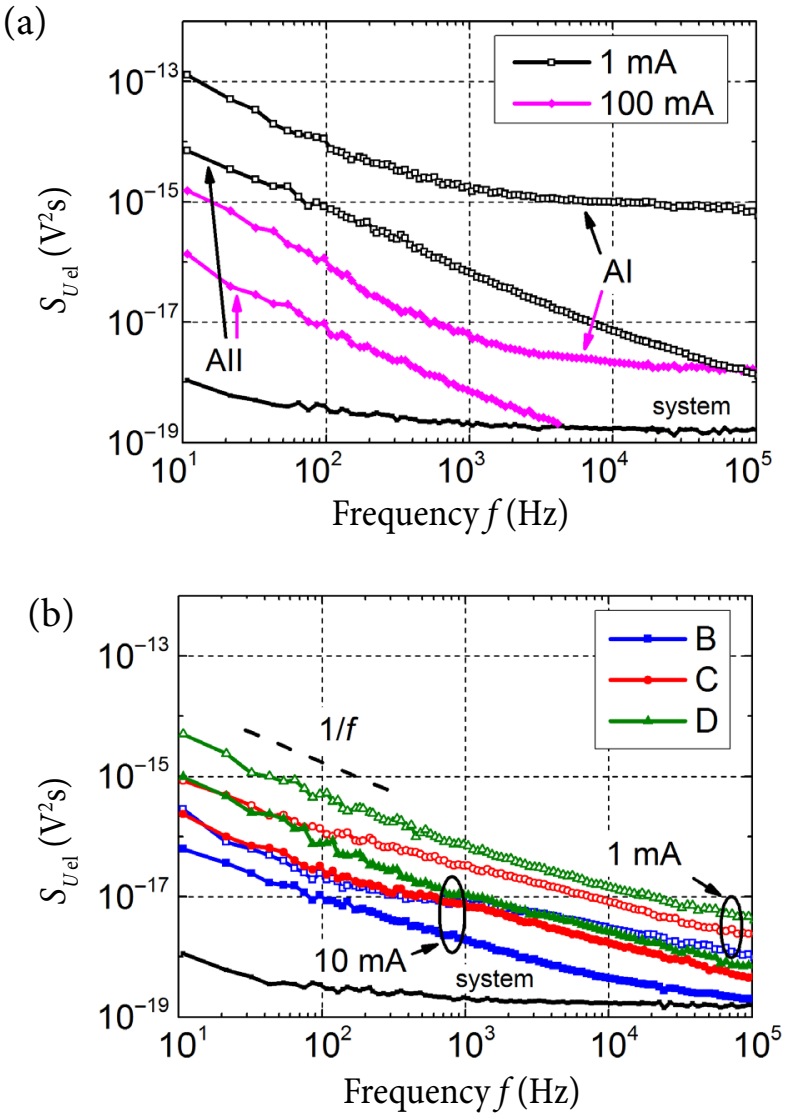

Fig. 5. Electrical noise spectra of the group A LEDs (a) and the LEDs of groups B-D (b) at different forward current values at RT. 'System' represents the measurement system noise floor.

charge carriers [6]. Thus, the tunnelling process in these AI samples can be considered as defect-assisted. Figure 1 (b), where the emitted light power characteristics for the samples of groups $\mathrm{A}$ and $\mathrm{D}$ are compared in log scales, confirms the idea of a high defectiveness of AI LEDs. The radiated optical power is proportional to the forward current as $U_{\text {opt }} \sim I^{r}$ [16], where the parameter $r>2$ for AI LEDs in a wide current interval up to $\sim 20 \mathrm{~mA}$ and $1<r<2$ for the $\mathrm{D}$ samples in a narrower interval (up to $\sim 1 \mathrm{~mA}$ ). In the case of AI LED a higher value of the parameter $r$ shows that the density of defects is higher in these devices compared to, for example, that of the group D LED (Fig. 1(b)). These defects act as non-radiative recombination centres and effectively lower the radiative efficiency of the device [6, 16].

The noise spectra of the AII and group B-D samples are characterized by $1 / f^{\alpha}$-type electrical fluctuations (Fig. 5) up to the forward current value where the series resistance-limited current arises. 


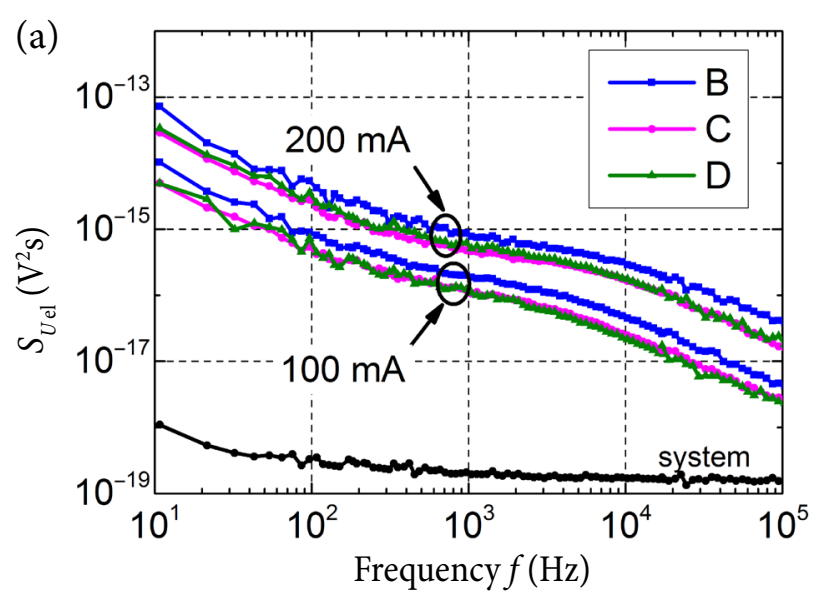

(b)

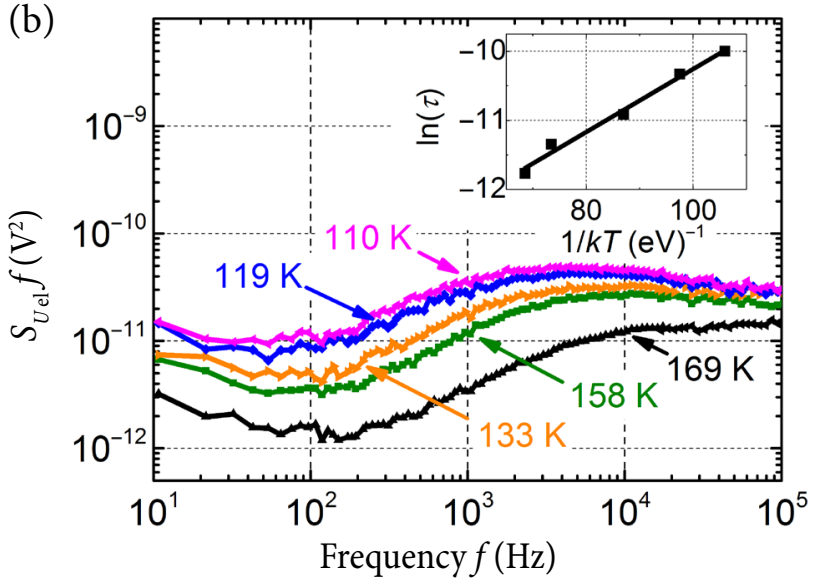

Fig. 6. Electrical noise spectra of the group B-D samples at RT in the series resistance-limited current regime (a); normalized electrical noise spectra $\left(S_{U \text { e }} f\right)$ of the group B LED in a temperature range of 110$169 \mathrm{~K}$ at $100 \mathrm{~mA}$ forward current (b). The inset in (b) represents the relaxation time dependence on the inverse temperature (square symbols denote experimental values)

As known, in semiconductor devices $1 / f^{\alpha}$-type fluctuations originate as a result of the superposition of Lorentzian-type spectra due to different capture and emission processes of charge carriers in defects with a very wide distribution of relaxation times [20, 21]. The series resistance-limited current tends to dominate at about $100 \mathrm{~mA}$ for the AII LEDs and for the samples of groups B-D at $5-50 \mathrm{~mA}$. While it is hard to determine these values from the $I-U$ characteristics accurately (Fig. 2), the dependences of electrical noise spectral density on the forward current clearly indicate that (Fig. 7). The series resistance $R_{\mathrm{s}}$ is mainly caused by resistances of contacts and highly doped $n^{+}$and $p$ layers. Thus, when the differential resistance of the LED reaches the serial resistance $\left(R_{\text {diff }} \approx R_{\mathrm{s}}\right)$, the electrical noise starts to increase
(Fig. 7). In the forward current range, where the voltage fluctuation spectral density decreases, the differential resistance of the diode $R_{\text {diff }} \sim 1 / I$, and for $1 / f^{\alpha}$-type electrical fluctuations the current noise spectral density for the $p n$ junction is proportional to the forward current: $S_{I} \sim I$ [22]. This leads to the relation $S_{U} \sim S_{I} \cdot R_{\text {diff }}^{2} \sim 1 / I$. Such observed ' $V$ '-shape dependences of voltage fluctuation spectral densities on the forward current are similar as for a phosphor-converted white LED with a 'blue' InGaN chip [11]. There only AI samples are distinguished by apparently higher noise level in a low current regime (up to $\sim 1 \mathrm{~mA}$, Fig. $7($ a) ) due to a high defectiveness as discussed earlier.

For the samples of groups B-D the voltage fluctuation spectral density increase that starts in a current interval of 5-50 mA is followed by the Lorentzian-type noise spectra appearance (Fig. $6(\mathrm{a})$ ). An
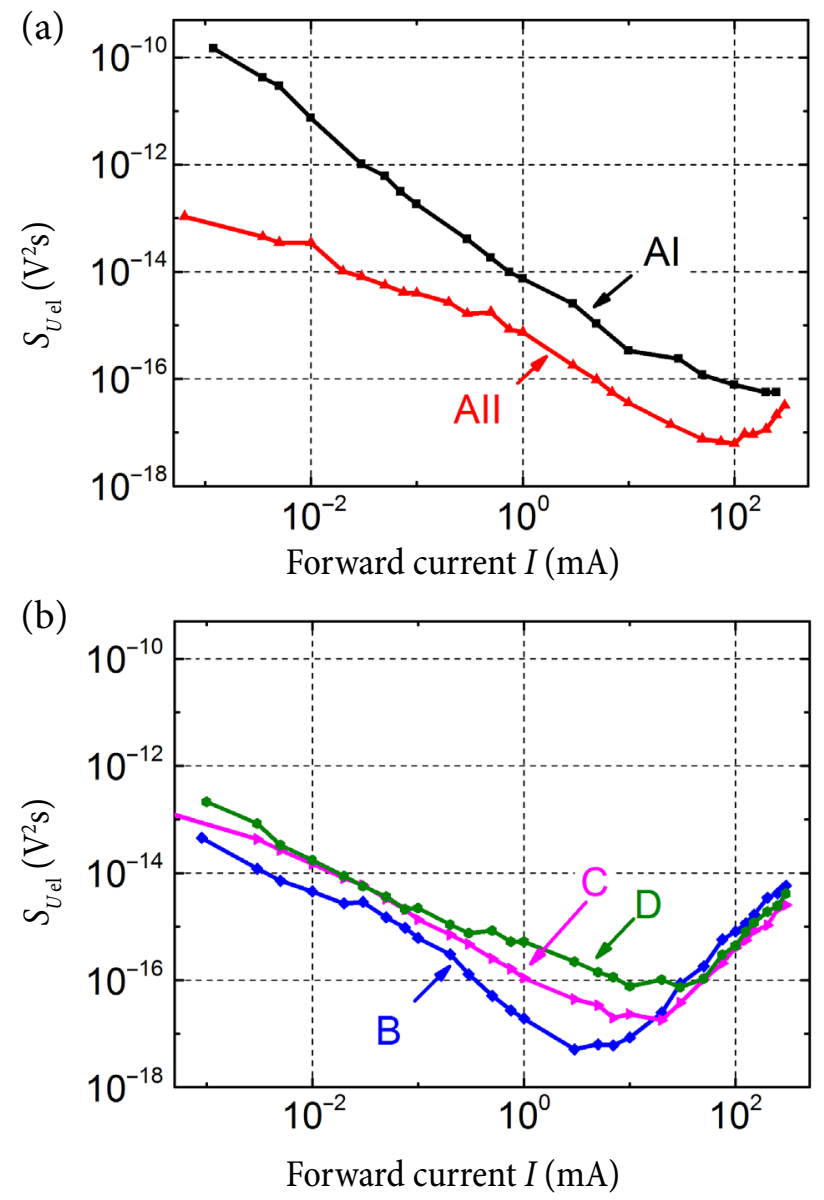

Fig. 7. Dependences of the voltage fluctuation spectral density $\left(S_{U \mathrm{Ul}}\right)$ on the forward current of the group A LEDs (a) and the LEDs of groups B-D (b) at $108 \mathrm{~Hz}$ frequency. 
example of the normalized electrical noise spectra $\left(S_{U \text { el }} f\right)$ of the group B LED at different temperatures is presented in Fig. 6(b). There noise peaks fulfil the condition $2 \pi f_{0} \tau=1$, where $f_{0}$ is the characteristic frequency of the spectrum maximum and $\tau$ is the effective relaxation time $(\tau \approx 8 \mu \mathrm{s}$ at RT). In a temperature interval of $170-293 \mathrm{~K}$ the noise maximum $S_{U \mathrm{el}} f$ position is practically independent of the temperature. This means that the Fermi level is bound to the accumulation of defect levels. It is assumed that these $\mathrm{g}-\mathrm{r}$ centres or interface states responsible for the mentioned fluctuations are located in the passive area of LED in highly doped $n^{+}$ or $p$ layers as the flowing current through the specimen is restricted by series resistance. In the interval of lower temperatures, the relaxation time dependence on temperature has been observed and the activation energy $E_{\mathrm{a}}$ of the responsible g-r process has been evaluated by the equation $\tau=\tau_{0} \exp \left(E_{a} /\right.$ $k T$ ) (the inset in Fig. $6(\mathrm{~b})$ ). The activation energy is determined to be in a range of $0.03-0.045 \mathrm{eV}$ for different B-D samples. The appearance of the $\mathrm{g}-\mathrm{r}$ noise component in the experiment for AII LEDs has been practically unnoticeable as $R_{\text {diff }}$ reaches $R_{\mathrm{s}}$ at higher currents $I>100 \mathrm{~mA}$ (Fig. 7 (a)).

Another g-r centre with $\sim 0.19 \mathrm{eV}$ activation energy has been identified in some samples of the group $\mathrm{B}$ in the $0.5-10 \mathrm{~mA}$ current region. The normalized electrical noise spectra of such LED at different temperatures are presented in Fig. 8. In the case of the group B sample the effective relaxation time

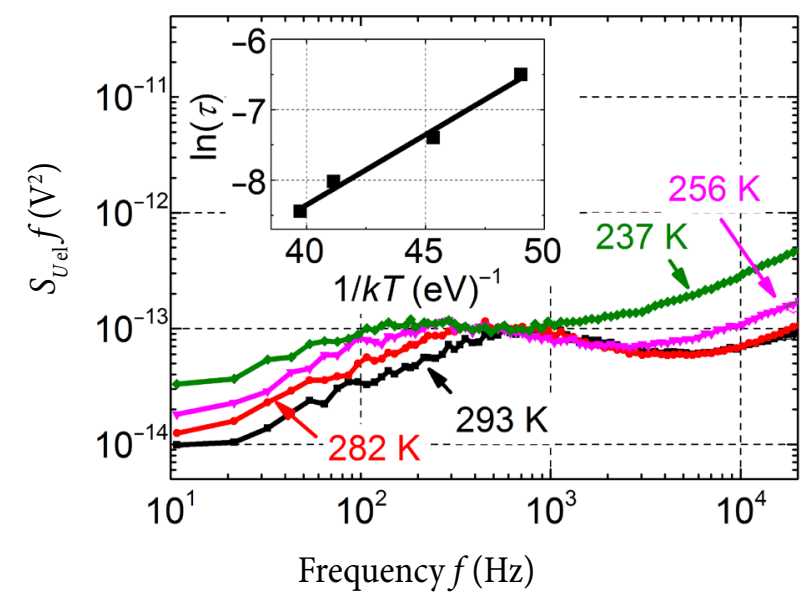

Fig. 8. Normalized electrical noise spectra $\left(S_{U \text { el }} f\right)$ of the group B LED in a temperature range of $237-293 \mathrm{~K}$ at $1 \mathrm{~mA}$ forward current. The inset represents the relaxation time dependence on the inverse temperature (square symbols denote experimental values).
( $\tau \approx 0.2 \mathrm{~ms}$ at $\mathrm{RT}$ ) is longer and the electrical noise level is also lower than in the case of AI LEDs, so it is expected that a different defect level is responsible for the observed Lorentzian-type fluctuations. For the verification of the discussed location of $g-r$ noise sources, cross-correlation analysis between electrical and optical fluctuations has been performed and it is presented in the next subsection.

\subsection{Cross-correlation coefficient between electrical and optical fluctuations}

The cross-correlation measurement between electrical and optical noise helps one to identify whether the low-frequency fluctuations originate from the active layer of LED or the peripheral ones [12]. The simultaneous cross-correlation coefficient is calculated as follows:

$$
k=\frac{\left\langle u_{\mathrm{el}}(t) \cdot u_{\mathrm{op}}(t)\right\rangle}{\left(\sigma_{\mathrm{el}}^{2} \cdot \sigma_{\mathrm{op}}^{2}\right)^{1 / 2}} .
$$

Here brackets $\langle\ldots\rangle$ mean averaging both over time and over number of realizations, $\sigma_{\mathrm{el}}^{2}=\left\langle u_{\mathrm{el}}^{2}(t)\right\rangle$ and $\sigma_{\text {op }}^{2}=\left\langle u_{\text {op }}^{2}(t)\right\rangle$ are the variances of electrical and optical, respectively, fluctuations in the frequency range from $10 \mathrm{~Hz}$ to $20 \mathrm{kHz}$. Note: for electrical and optical noise signals $\left[\left\langle u_{\mathrm{el}}(t)\right\rangle\right]^{2}=0$ and $\left[\left\langle u_{\mathrm{op}}(t)\right\rangle\right]^{2}=0$.

The optical noise spectra of the investigated samples are presented in Fig. 9(a). As seen, the group A LEDs are distinguished by stronger optical $1 / f^{\alpha}$-type fluctuations (up to $\sim 5 \mathrm{kHz}$ ) than the samples from the groups B-D. The normalized optical noise $S_{\text {Uopt }}$, $U^{2}$ opt of the family A LEDs is significantly higher than the noise of the remaining samples at frequencies where $1 / f^{\alpha}$-type optical fluctuations dominate (Fig. 9 (b)). Here in Fig. 9(b) $S_{U \text { Upt }} / U_{\text {opt }}^{2}$ decreases as the forward current increases due to the light power increase. At higher frequencies (above $\sim 5 \mathrm{kHz}$ ) the optical noise is 'white' - the spectrum is determined by the photocurrent induced shot noise (Fig. $9(\mathrm{a})$ ).

Figure 10 shows that the highest cross-correlation coefficient between electrical and optical fluctuations is for group AI LEDs (up to 70\%). This indicates a high defectiveness of the active area of LED, which leads to suppose that the earlier observed trap level in the group AI LEDs is also related to the structure of QWs and barrier layers. 


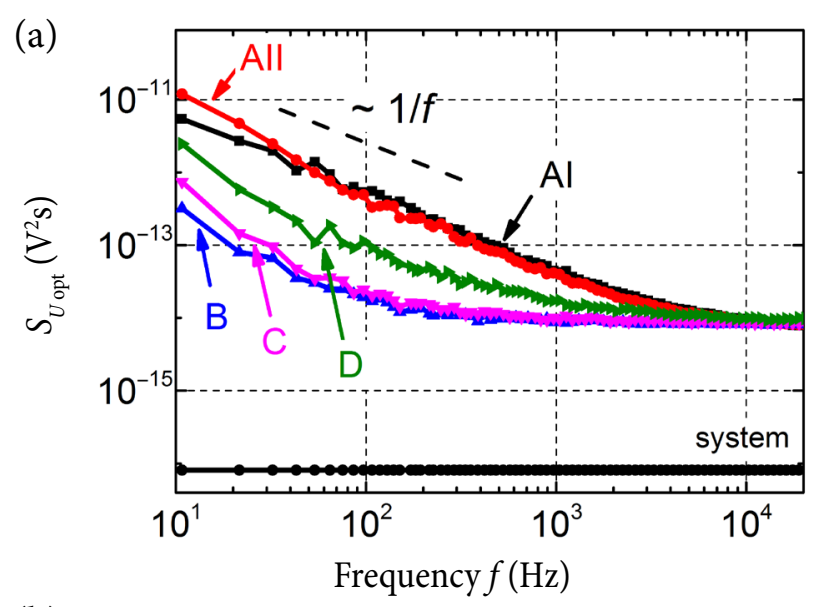

(b)

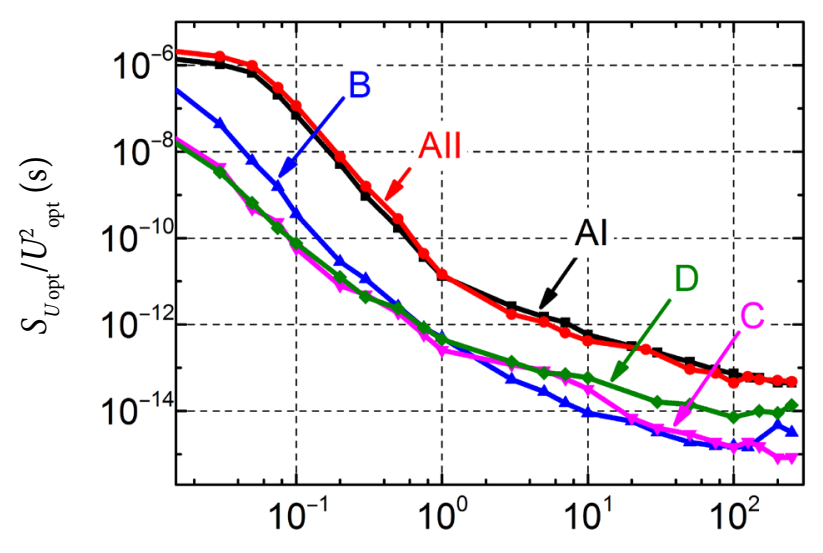

Forward current $I(\mathrm{~mA})$

Fig. 9. Optical noise spectra $\left(S_{U_{0}}\right)$ of the investigated LEDs at $100 \mathrm{~mA}$ forward current (a); dependences of the voltage spectral density of the normalized optical noise $\left(S_{U o p t} / U_{\text {opt }}^{2}\right)$ on the forward current for the investigated samples at $108 \mathrm{~Hz}$ frequency (b).
For the families of other samples the cross-correlation coefficient is lower and its maximum value varies in the forward current interval from 2 to $10 \mathrm{~mA}$ (Fig. 10(b)). At low current values optical $1 / f^{\alpha}$-type or $\mathrm{g}-\mathrm{r}$ noise components are too small to correlate effectively with the electrical noise. At higher current values the shot noise level increases drastically in the optical noise spectra and the electrical noise from the peripheral or contact areas of LED also starts to dominate. This explains different forward current values corresponding to the cross-correlation coefficient maxima. For the samples of groups B-D at $I>50 \mathrm{~mA}$ the coefficient becomes even slightly negative (down to $-8 \%$, Fig. 10(b)). The negative cross-correlation indicates the forward current redistribution between the active and passive layers of LED [23] due to defects located in the vicinity of the active QW region. Practically, no positive cross-correlation in the series resistance-limited current regime verifies that the detected noise sources responsible for the Lorentzian-type fluctuations are in the peripheral area of LED.

A comparison between the LEDs of group B with or without a $\mathrm{g}-\mathrm{r}$ component in the noise spectra shows that devices with Lorentzian-type fluctuations in a current interval of $0.5-10 \mathrm{~mA}$ have a higher cross-correlation coefficient (Fig. 10(b)). There are no dramatic changes in the electrical noise level between these samples in this current regime. However, a stronger correlation between
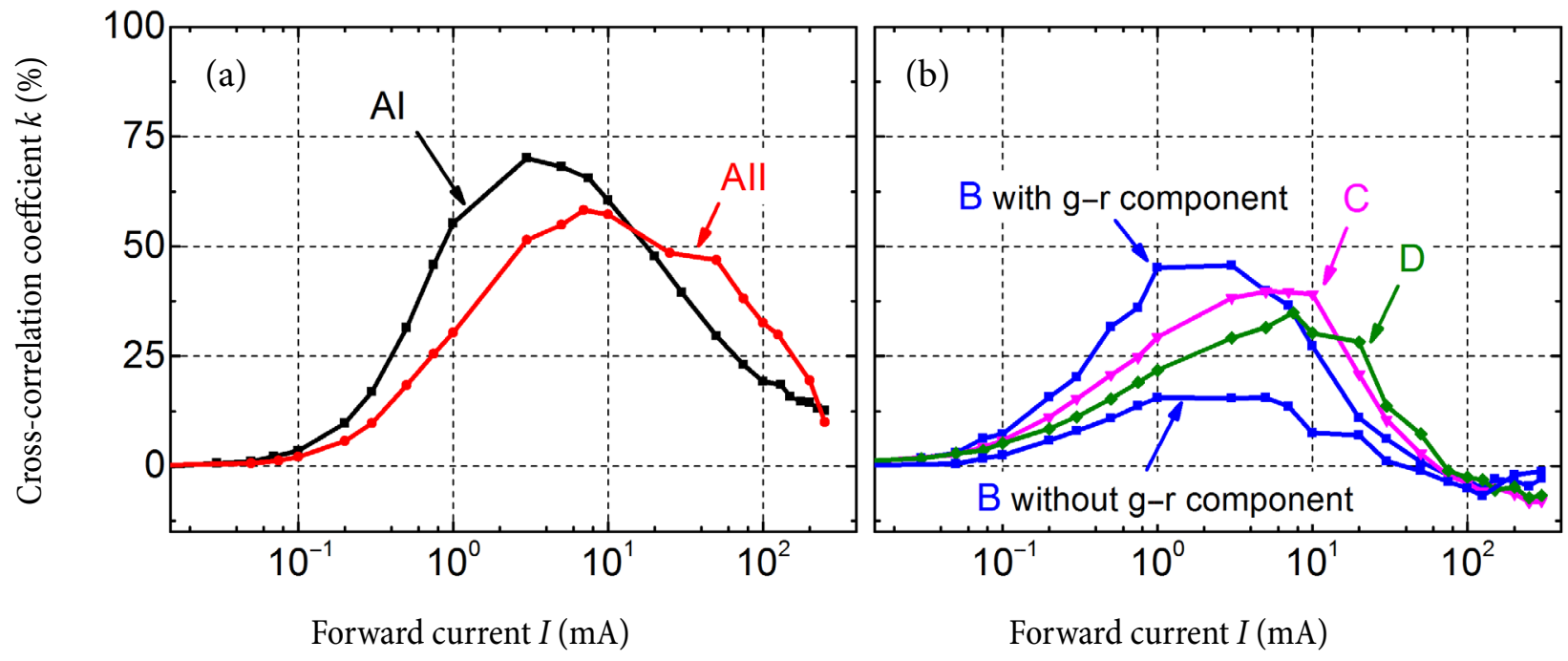

Fig. 10. Dependences of the cross-correlation coefficient between electrical and optical fluctuations on the forward current in the frequency range from $10 \mathrm{~Hz}$ to $20 \mathrm{kHz}$ for the group A LEDs (a) and the LEDs of groups B-D (b). 
the electrical and optical fluctuations in the $\mathrm{B}$ samples with the detected $\mathrm{g}-\mathrm{r}$ noise component suggests that the part of electrical noise arising in the active layer of LED in this case is higher than in the case of specimens without a g-r noise component. There the total electrical noise can be expressed as $S_{\text {el total }}=S_{\text {el corr }}+S_{\text {el uncorr }}$ where $S_{\text {el corr }}$ represents the part of electrical fluctuations related to the active layer of the LED and $S_{\text {el uncorr }}$ is the part of electrical fluctuations arising from the peripheral area of the LED [12]. Thus, the observed Lorentzian-type fluctuations are determined by the presence of an additional defect level in the active InGaN QW region of some group B LEDs.

\section{Conclusions}

Investigation of the low-frequency noise characteristics of high power near UV LEDs has been performed. The tunnelling current component has been detected in some $380 \mathrm{~nm}$ peak wavelength LEDs at low bias. Such samples are distinguished by the Lorentzian-type electrical noise spectra in the whole investigated current range and a strong cross-correlation between electrical and optical fluctuations exists. This identifies the location of the trapping level in the active area of this group LEDs and contributes to the tunnelling process through defects.

LEDs of other groups with a peak wavelength of 390,400 and $410 \mathrm{~nm}$ are characterized by the $1 / f^{\alpha}$-type electrical fluctuations with Lorentziantype noise components appearing only at the series resistance-limited currents. Defect levels with the activation energy in a range of $0.03-0.045 \mathrm{eV}$ have been identified responsible for these $\mathrm{g}-\mathrm{r}$ fluctuations. No positive cross-correlation between electrical and optical fluctuations in this current regime means that the Lorentzian-type fluctuation source is in the peripheral area of the LED, e.g. in highly doped layers.

Some of $390 \mathrm{~nm}$ peak wavelength LEDs are distinguished by an additional Lorentzian-type noise component in a current range of $0.5-10 \mathrm{~mA}$ with $0.19 \mathrm{eV}$ activation energy. Such samples have a higher cross-correlation between electrical and optical fluctuations than samples with only $1 / f^{\alpha}$-type noise spectra. This suggests that the location of the detected $\mathrm{g}-\mathrm{r}$ noise centre is related to the InGaN QW structure.

\section{References}

[1] Y. Muramoto, M. Kimura, and S. Nouda, Development and future of ultraviolet light-emitting diodes: UV-LED will replace the UV lamp, Semicond. Sci. Technol. 29, 1-8 (2014).

[2] D. Morita, M. Sano, M. Yamamoto, T. Murayama, S. Nagahama, and T. Mukai, High output power $365 \mathrm{~nm}$ ultraviolet light emitting diode of GaNfree structure, Jpn. J. Appl. Phys. 41, L1434L1436 (2002).

[3] J.T. Oh, Y.T. Moon, D.S. Kang, C.K. Park, J.W. Han, M.H. Jung, Y.J. Sung, H.H. Jeong, J.O. Song, and T.Y. Seong, High efficiency ultraviolet GaN-based vertical light emitting diodes on 6-inch sapphire substrate using ex-situ sputtered AlN nucleation layer, Opt. Express 26, 5111-5117 (2018).

[4] K.C. Shen, W.Y. Lin, H.Y. Lin, K.Y. Chen, and D.S. Wuu, Self-textured oxide structure for improved performance of $365 \mathrm{~nm}$ ultraviolet vertical-type light-emitting diodes, Opt. Express 22, 17600-17606 (2014).

[5] P. Ruterana, S. Kret, A. Vivet, M. Grzegorz, and P. Dłużewski, Composition fluctuation in InGaN quantum wells made from molecular beam or metalorganic vapor phase epitaxial layers, J. Appl. Phys. 91, 8979-8985 (2002).

[6] X.A. Cao, K. Topol, F. Shahedipour-Sandvik, J. Teetsov, P.M. Sandvik, S.F. LeBoeuf, A. Ebong, J. Kretchmer, E.B. Stokes, S. Arthur, A.E. Kaloyeros, and D. Walker, Influence of defects on electrical and optical characteristics of GaN/ InGaN-based light-emitting diodes, Proc. SPIE 4776, 105-113 (2002).

[7] L.K.J. Vandamme, Noise as diagnostic tool for quality and reliability of electronic devices, IEEE Trans. Electron Dev. 41, 2176-2187 (1994).

[8] S. Bychikhin, D. Pogany, L.K.J. Vandamme, G. Meneghesso, and E. Zanoni, Low-frequency noise sources in as-prepared and aged $\mathrm{GaN}$ based light-emitting diodes, J. Appl. Phys. 97, 123714 (2005).

[9] S.L. Rumyantsev, C. Wetzel, and M.S. Shur, Wavelength-resolved low-frequency noise of GaInN/GaN green light emitting diodes, J. Appl. Phys. 100, 084506 (2006). 
[10]A.E. Chernyakov, M.E. Levinshtein, N.A. Talnishnikh, E.I. Shabunina, and N.M. Shmidt, Low-frequency noise in diagnostics of power blue InGaN/GaN LEDs, J. Cryst. Growth 401, 302-304 (2014).

[11]J. Glemža, J. Matukas, S. Pralgauskaitè, and V. Palenskis, Low-frequency noise characteristics of high-power white LED during long-term aging experiment, Lith. J. Phys. 58, 194-203 (2018).

[12]V. Palenskis, J. Matukas, S. Pralgauskaite, and B. Šaulys, A detail analysis of electrical and optical fluctuations of green light-emitting diodes by correlation method, Fluctuation Noise Lett. 9, 179-192 (2010).

[13]I.H.Lee, A.Y. Polyakov, S.M. Hwang, N.M. Shmidt, E.I. Shabunina, N.A. Tal'nishnih, N.B. Smirnov, I.V. Shchemerov, R.A. Zinovyev, S.A. Tarelkin, and S.J. Pearton, Degradation-induced low frequency noise and deep traps in GaN/InGaN near-UV LEDs, Appl. Phys. Lett. 111, 062103 (2017).

[14]J. Kim, Y. Tak, J. Kim, S. Chae, J.Y. Kim, and Y. Park, Analysis of forward tunneling current in InGaN/GaN multiple quantum well light-emitting diodes grown on Si (111) substrate, J. Appl. Phys. 114, 013101-1-4 (2013).

[15]P. Perlin, M. Osinski, P.G. Eliseev, V.A. Smagley, J. Mu, M. Banas, and P. Sartorid, Low-temperature study of current and electroluminescence in InGaN/AlGaN/GaN double-heterostructure blue light-emitting diodes, Appl. Phys. Lett. 69, 16801682 (1996).
[16]X.A. Cao, E.B. Stokes, P.M. Sandvik, S.F. LeBoeuf, J. Kretchmer, and D. Walker, Diffusion and tunneling currents in $\mathrm{GaN} / \mathrm{InGaN}$ multiple quantum well light-emitting diodes, IEEE Electron Device Lett. 23, 535-537 (2002).

[17]M. Lee, H. Lee, K.M. Song, and J. Kim, Investigation of forward tunneling characteristics of InGaN/GaN blue light-emitting diodes on freestanding $\mathrm{GaN}$ detached from a $\mathrm{Si}$ substrate, Nanomaterials 8, 543-1-7 (2018).

[18] V.K. Malyutenko and S.S. Bolgov, Effect of current crowding on the ideality factor in MQW InGaN/GaN LEDs on sapphire substrates, Proc. SPIE 7617, 76171K (2010).

[19]M.J. Kirton and M.J. Uren, Noise in solid-state microstructures: A new perspective in individual defects, interface states and low-frequency $(1 / f)$ noise, Adv. Phys. 38, 367-468 (1989).

[20]V. Palenskis and K. Maknys, Nature of low-frequency noise in homogenous semiconductors, Sci. Rep. 5, 18305-1-7 (2015).

[21]V. Palenskis, The charge carrier capture-emission process - the main source of the low-frequency noise in homogeneous semiconductors, Lith. J. Phys. 56, 200-206 (2016).

[22]F.N. Hooge, T.G.M. Kleinpenning, and L.K.J. Vandamme, Experimental studies on 1/f noise, Rep. Prog. Phys. 44, 479-532 (1981).

[23]V. Palenskis, J. Matukas, and S. Pralgauskaité, Light-emitting diode quality investigation via low-frequency noise characteristics, Solid State Electron. 54, 781-786 (2010). 


\section{ARTIMOSIOS UV SRITIES ŠVIESOS DIODŲ ŽEMADAŽNIAI TRIUKŠMAI}

J. Glemža, S. Pralgauskaitė, V. Palenskis, J. Matukas

Vilniaus universiteto Taikomosios elektrodinamikos ir telekomunikaciju institutas, Vilnius, Lietuva

\section{Santrauka}

Atlikti didelès galios artimosios ultravioletinès (UV) srities šviesos diodų su smailiniu bangos ilgiu 380$410 \mathrm{~nm}$ intervale žemadažnio triukšmo charakteristikų tyrimai 110-293 K temperatūroje. Kai kurie $380 \mathrm{~nm}$ smailinio bangos ilgio bandiniai turi vyraujančią tunelinės srovès komponentę, atsirandančią dèl defektų, esant pridètai žemai ịtampai, ir pasižymi generacinio-rekombinacinio triukšmo spektriniais tankiais visame tirtame srovių intervale. Likę bandiniai yra charakterizuojami $1 / f^{\alpha}$-tipo fliuktuacijomis, tačiau, pasiekus nuoseklios varžos ribojamą laidumo sriț̨, triukšmų spektriniuose tankiuose išryškèja papildoma generacinio-rekombi- nacinio triukšmo komponentè. Dalis $390 \mathrm{~nm}$ smailinio bangos ilgio bandinių srovių 0,5-10 mA intervale taip pat pasižymi generacinio-rekombinacinio tipo fliuktuacijomis. Generacinio-rekombinacinio triukšmo spektroskopija rastos šių krūvininkų pagavimo lygmenų aktyvacijos energijos. Siekiant nustatyti triukšmo šaltinių vietą bandinyje ir ịvertinti, ar minèti defektų lygmenys yra susiję su aktyviąja ar pasyviąja šviesos diodo sritimi, buvo atlikta abipusés koreliacijos koeficiento tarp elektrinių ir optinių fliuktuacijų analizé $10 \mathrm{~Hz}-20 \mathrm{kHz}$ dažnių srityje. Tobulinant šviesos diodų gamybos technologiją, triukšmo šaltinių vietos nustatymas yra ypač svarbus. 